\title{
Exercise Guidelines for CKD Patients
}

\author{
Rita Huie* \\ Department of Nutrition and Food Services, Central Arkansas Veterans Healthcare Systems, USA
}

Submission: February 01, 2017; Published: March 21, 2017

*Corresponding author: Department of Nutrition and Food Services, Central Arkansas Veterans Healthcare Systems, USA, Email: Rita.Milam@va.gov

\begin{abstract}
Chronic Kidney Disease (CKD) patients are often overlooked when it comes to exercise programs [1]. Although, the medical community, specifically, a majority of nephrologists are of the opinion that their patients should engage in regular exercise to improve overall health [2]. Physical inactivity contributes to a reduction in activities of daily living and reduced quality of life [3]. By enhancing the strength of their muscles, bones, and joints through exercising, people with CKD can improve their balance and coordination [4]. This can further prevent them from falling and likewise, protect their independence as they age. Moreover, it is widely known that CKD patients are at high risk for premature death as a result of cardiovascular disease due in part to their sedentary behavior [5]. By increasing the physical activity levels of individuals with CKD, it's possible to decrease their risk of cardiovascular disease and improve their physical functioning, thus thwarting premature death [6].
\end{abstract}

More recently, studies have looked at the possibility that increasing physical activity levels may slow the rate of decline of estimated glomerular filtration rate (eGFR) in patients with CKD stages 3 to 4. The latest Kidney Disease Improving Global Outcomes (KDIGO) Clinical Practice Guideline for the Evaluation and Management of Chronic Kidney Disease lifestyle section recommends that individuals with CKD engage in physical activity for at least 30 minutes per day, 5 times per week [7].

Besides counseling CKD patients on diet modifications, registered dietitian nutritionists (RDNs) especially those with expertise in renal nutrition and nephrology are in a position to also aid their patients in recommendations for increasing their physical activity levels. The RDN should begin by determining in their initial nutritional assessment, the activity level of the CKD patient. A Low Physical Activity Questionnaire (LoPAQ) has been developed to assess and could be further used for monitoring physical activity. Although it was constructed for patients on hemodialysis, this instrument would also be pertinent for use with the CKD patient population. After identifying areas to improve on, the RDN may recommend structured activities including aerobic, strength, and flexibility exercises. A combination of all three types of exercises performed five times a week using different muscle groups each day would improve the CKD patient's endurance and strength [8].

It is important that the RDN ensure that the exercises suggested be individualized to the CKD patient's current stage of physical ability. Implementing an exercise program along with diet modifications can be challenging for both the RDN and the CKD patient. However, with continued follow-up monitoring and adjustments along the way, patients with CKD can improve their overall health. The corresponding patient education handout is designed to provide clinicians with a starting point in addressing an exercise program with their CKD patients.

Keywords: Physical activity; Exercise; Chronic Kidney Disease (CKD); KDIGO; LoPAQ

\section{Intended Audience: CKD}

\section{Why Exercise?}

People with Chronic Kidney Disease (CKD) can benefit from exercising regularly just like those without this condition. Your quality of health can improve if you can engage in activities that strengthen the muscles, bones, and joints in your body. This can improve your balance and coordination which can prevent you from falls and protect your independence as you get older.

Other physical exercise benefits also include better blood pressure and diabetes control. Sometimes these diseases can worsen when the kidneys are damaged and more medications may have to be added to those that you are already taking.
Exercising regularly may help lower your blood pressure and keep it from further damaging the kidneys. In the same way, exercise helps to lower your blood sugar levels throughout the day and night and puts less stress on the kidneys.

\section{What types of exercises are best?}

Structured activities include aerobic, strength, and flexibility activities. Aerobic activities are where you use large amounts of oxygen. These types of exercises include walking, jogging, stair climbing, swimming, water walking and water aerobics, gardening, dancing, bicycling, and chair exercises. Other types of aerobic exercises can be performed on machines such as a treadmill, stationary bike, or elliptical trainer. Strength training 
involves using large muscles of your body to perform activities. For instance, free weights or dumbbells, resistance bands and tubes, Pilates, and medicine balls aid in strengthening your muscles.Flexibility type activities move your joints through their full range of motion and help to lessen your risk of injury when performing physical activities. These include stretching, Yoga, and Tai Chi.

\section{How much should I exercise?}

If you haven't already been exercising regularly, you will want to start slowly and work upto a pace that you are comfortable with each day. Ideally, you will want to engage in exerciseaerobic, strengthening, or flexibility activities -5 times per week. If you can get in a habit of exercising at the same time each day, it will be less of a chore and more of a routine of living healthfully, just like eating your meals.For instance, begin and end your work-out with stretching exercises, follow with either an aerobic activity such as walking or strength training such as lifting hand- held weights. A combination of these activities using different muscle groups each day such as the upper body one day and the lower body another, will improve your health over time.

\section{How can I stay safe while exercising?}

The main thing to remember when exercising is to listen to your body. Keep in mind that exercising regularly is healthier than not exercising at all. But with that said, if you do develop any of the following problems, stop what you are doing and seek medical help:

A. Unusual shortness of breath

B. Pain in the upper part of your body including your jaw

C. Nausea or vomiting

D. Cramping of muscles or joint pain

E. Sudden weakness especially in your limbs

F. Trouble with eyesight, speech, or difficulty swallowing

G. Sudden onset headache, dizziness, or a feeling of lightheadedness

H. Chronic Kidney Disease should not hold you back from living more fully. It just may mean that that you will need to put forth more effort in improving your health with the addition of exercising regularly. You may want to seek out support from family and friends to help you along the way. Often, you need the encouragement of others to motivate you to continue to stay on course. So, don't hesitate in asking those close to you for their help.

\section{Sample Exercises}

Aerobic

Walking Program:
1. Begin by walking at a slow but steady pace for 10 minutes 5 days a week.

2. Once comfortable with the walking 10 minutes daily, then increase to 20 minutes every other day at a brisk pace.

3. At one month, increase your time to 30 minutes every other day.

4. Then, after one month, walk 30 minutes 5 times a week.

At this point, you will be walking long enough and with the right amount of effort to support physical benefits to improve your health.

\section{Strength}

Toe Raises:

1. Stand straight with your hands on a counter or rail for support. Slowly raise your heels up off the floor and count to two.

2. Then lower your heels back down to the floor. Repeat 8-12 times.

Leg Lifts:

1. Sit in a chair where your back is straight and your knees are bent and feet are flat on the floor. Lift and straighten your right leg and hold for a few seconds. Lower your right leg to the starting position.

2. Repeat using your left leg. Perform exercise 8-12 times with each leg.

\section{Flexibility}

Stretching exercises will help to lengthen and loosen your muscles and joints. Perform these as a warm-up and cool-down part of your overall exercise plan.

Shoulder Rotation:

1. While standing or sitting, move the top of your right shoulder forward in a circular motion for 15-30 seconds.

2. Repeat with your left shoulder.

Leg stretch:

1. While lying on your back, bend your right leg and keep your left leg straight.

2. With both your hands placed behind your right leg, pull your thigh toward your chest and hold for 15-30 seconds.

3. Repeat with your left leg.

\section{References}

1. Delgado C, Johansen (2010) Deficient counseling on physical activity among nephrologists. Nephron ClinPract 116: c330-c336.

2. Howden EJ, Coombes JS, Strand H, Douglas B, Campbell KL, et al. (2015) Exercise training in CKD: efficacy, adherence, and safety. Am J Kidney Dis 65(4): 583-591. 
3. Hiraki K, Yasuda T, Hotta C, Izawa KP, Morio Y, et al. ( 2013) Decreased physical functioning pre-dialysis patients with chronic kidney disease. ClinExp Nephrol 17(2): 225-231.

4. Chan M, Singh B, Fiatarone Singh MA (2007) Progressive resistance training and nutrition in renal failure. J Ren Nutr 17(1): 84-87.

5. Greenwood SA, Koufaki P, Mercer TH, MacLaughlin HL, Rush R, et al (2015) Effect of exercise training on estimated GFR, vascular health, and cardiorespiratory fitness in patients with CKD: a pilot randomized controlled trial. Am J Kidney Dis 65(3): 425-434.

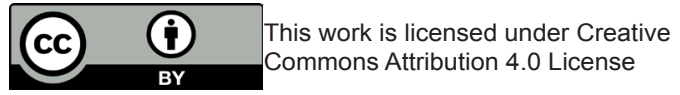

6. Castaneda C, Gordon PL, Uhlin KL, Levey AS, Kehayias JJ (2001) Resistance training to counteract the catabolism of a low-protein in patients with chronic kidney disease. Ann Intern Med 135: 965-976.

7. (2013) KDIGO 2012 Clinical Practice Guideline for the Evaluation and Management of Chronic Kidney Disease. Kidney Int 3(1): 79-80.

8. Johansen KL, Painter P, Delgado C, Doyle J (2015) Characterization of physical activity and sitting time among patients on hemodialysis using a new physical activity instrument. J Ren Nutr 25: 25-30.

\section{Your next submission with Juniper Publishers will reach you the below assets}

- Quality Editorial service

- Swift Peer Review

- Reprints availability

- E-prints Service

- Manuscript Podcast for convenient understanding

- Global attainment for your research

- Manuscript accessibility in different formats

( Pdf, E-pub, Full Text, Audio)

- Unceasing customer service

Track the below URL for one-step submission https://juniperpublishers.com/online-submission.php 